\title{
Current and future role of biomarkers in Crohn's disease risk assessment and treatment
}

This article was published in the following Dove Press journal:

Clinical and Experimental Gastroenterology

I June 201 I

Number of times this article has been viewed

Cyrus P Tamboli'

David B Doman ${ }^{2}$

Amar Patel ${ }^{3}$

'Department of Internal Medicine, Division of Gastroenterology,

University of lowa, lowa City, IA, USA; ${ }^{2}$ George Washington School of Medicine, Silver Spring, MD, USA; ${ }^{3}$ Peloton Advantage, LLC, Parsippany, NJ, USA
Correspondence: Cyrus P Tamboli Department of Internal Medicine, Division of Gastroenterology, University of lowa, lowa City, IA 52242-I08I, USA $\mathrm{Tel}+\mid 319384984$ I

Fax + I 3193536399

Email cyrus-tamboli@uiowa.edu
Background: Crohn's disease (CD), a chronic inflammatory bowel disease (IBD), occurs in genetically susceptible individuals who develop aberrant immune responses to endoluminal bacteria. Recurrent inflammation increases the risk of several complications. Despite use of a traditional "step-up" therapy with corticosteroids and immunomodulators, most CD patients eventually require surgery at some time in their disease course. Newer biologic agents have been remarkably effective in controlling severe disease. Thus, "top-down," early aggressive therapy has been proposed to yield better outcomes, especially in complicated disease. However, safety and cost issues mandate the need for careful patient selection. Identification of high-risk candidates who may benefit from aggressive therapy is becoming increasingly relevant. Serologic and genetic markers of CD have great potential in this regard. The aim of this review is to highlight the clinical relevance of these markers for diagnostics and prognostication.

Methods: A current PubMed literature search identified articles regarding the role of biomarkers in IBD diagnosis, severity prediction, and stratification. Studies were also reviewed on the presence of IBD markers in non-IBD diseases.

Results: Several IBD seromarkers and genetic markers appear to be associated with complex $\mathrm{CD}$ phenotypes. Qualitative and quantitative serum immune reactivity to microbial antigens may be predictive of disease progression and complications.

Conclusion: The cumulative evidence provided by serologic and genetic testing has the potential to enhance clinical decision-making when formulating individualized IBD therapeutic plans.

Keywords: Crohn's disease, serologic testing, inflammatory bowel disease, complicated disease, biomarkers

\section{Introduction}

Crohn's disease (CD) is a prevalent chronic inflammatory bowel disease (IBD) marked by heterogeneous symptoms indicative of an underlying inflammatory process. The hallmark pathology of CD is chronic transmural inflammation, but the phenotypic spectrum varies greatly both in location and behavior (ie, stricturing or penetrating phenotypes). ${ }^{1}$ As the disease progresses, persisting inflammation may lead to penetration and strictures, perhaps culminating in medically refractory disease requiring multiple hospitalizations and surgical intervention. ${ }^{2-4}$ The traditional treatment paradigm includes a "step-up" approach of corticosteroids and immunomodulators, with or without biologic agents as severity progresses or patients fail to respond. ${ }^{5-7}$ Whereas this approach may be effective in the near term, ${ }^{8-10}$ it may not prevent overall disease progression. ${ }^{11-13}$ Within 10 years of diagnosis, more than half of CD patients still require surgical resection within 20 years, ${ }^{14}$ approximately $50 \%-70 \%$ of CD patients develop 
a stricturing or penetrating intestinal complication, ${ }^{2,15}$ and the cumulative risk of hospitalization rises to nearly $80 \%{ }^{16}$ Risk of hospitalization is greatest within the first year after diagnosis of CD (32\%-83\% of patients), with the annual incidence of hospitalizations remaining steady at $20 \%$ over the next 5 years. ${ }^{16,17}$

"Top-down" therapy, ${ }^{7,18}$ with the earlier introduction of biologic agents such as antitumor necrosis factor alpha (anti-TNF- $\alpha$ ) antibodies, has demonstrated high rates of remission and mucosal healing. ${ }^{19-23}$ However, the top-down approach is not appropriate for all patients, as not all of them will develop complicated disease. ${ }^{2,12,16}$ Early use of immunosuppressants or biologics soon after diagnosis may increase the risks, including malignancies and infections. ${ }^{7,18}$ The high costs of these therapies ${ }^{24,25}$ also prohibit top-down therapy as a universal approach. ${ }^{7}$ Therefore, the ability to identify patients at risk for developing a complicated disease course is critical to the effective use of targeted top-down strategies.

\section{Clinical and nonserologic predictors of disease course}

Clinical features have some predictive value for prognosis in $\mathrm{CD}$, but their interpretation remains problematic. Studies have shown that an initial requirement for steroids, young age at diagnosis, presence of small bowel, and/or perianal disease at diagnosis, and cigarette smoking ${ }^{26-28}$ are associated with an adverse prognosis. However, factors such as referral bias, ${ }^{29}$ varying definitions of adverse outcomes, and varying prior disease treatments in these studies complicate the prognosis and make predictions difficult for the individual CD patient. Clinical phenotyping issues remain complex; ongoing efforts are being made to standardize a clinical classification scheme for IBD. ${ }^{30}$ Disease localization may be comparable only at the time of diagnosis, since CD behavior evolves over time. Vernier-Massouille et $\mathrm{al}^{31}$ showed a convergence in rates of CD subtypes, with inflammatory (decreasing prevalence) and stricturing (increasing prevalence) disease over 10 years of follow-up after diagnosis (Figure 1). Most studies suggest that ileal disease is an independent predictor of adverse outcomes, particularly the need for early surgery. ${ }^{29,32-34}$ While some clinical features do show associations with adverse prognosis, they are usually described retrospectively, and many features lack standardization. The resulting heterogeneity leads to significant difficulty in using these clinical data for creating therapeutic algorithms in CD. ${ }^{35}$

Inflammatory biomarkers such as C-reactive protein (CRP), fecal calprotectin, and fecal lactoferrin may be useful in differentiating active IBD from inactive IBD and other

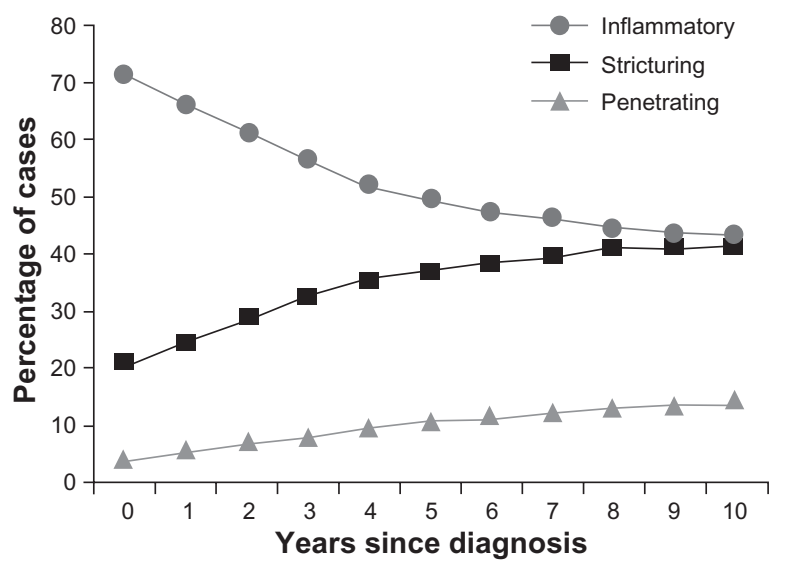

Figure I Crohn's disease phenotypic behavior over time, according to Montreal classification at diagnosis and follow-up in 404 pediatric patients. Dramatic changes occurred in the proportion of disease behavior subgroups - from inflammatory nonpenetrating, nonstricturing disease $(\mathrm{BI})$ to stricturing (B2) or penetrating disease (B3) $(P<0.01)$.

Copyright $@$ 2004, Elsevier. Reproduced with permission from Vernier-Massouille et al. ${ }^{31}$

gastrointestinal disorders, ${ }^{36}$ as well as measuring response to various treatments. ${ }^{37}$ Pretreatment CRP levels have shown utility in predicting treatment response to anti-TNF- $\alpha$ agents in CD in some but not all studies. ${ }^{20,38}$ The value of CRP as a pretreatment predictor of severe disease remains mostly unknown. Henriksen et $\mathrm{al}^{39}$ found a CRP $>53 \mathrm{mg} / \mathrm{L}$ at diagnosis to be predictive of a high risk of surgery $(82 \%)$ after 5 years in patients with ileal disease (odds ratio [OR] $6.0 ; 95 \%$ confidence interval [CI] 1.1-31.9), L1 according to the Vienna classification. Although the predictive value of an elevated CRP is suggested in this subset $(-30 \%$ of those with L1 classification), ${ }^{39}$ the sensitivity and specificity of CRP in $\mathrm{CD}$ are modest overall. Fecal calprotectin is a natural antibiotic, cytoplasmic protein released into the colonic lumen by activated polymorphonuclear neutrophil cells and/or monocyte-macrophages during cell death. Fecal calprotectin levels are elevated in active IBD. Lactoferrin, similar to calprotectin, is a glycoprotein component of polymorphonuclear neutrophil granules whose concentrations become elevated in feces during an acute mucosal inflammatory response. Four fecal markers of inflammation - calprotectin (PhiCal ${ }^{\mathrm{TM}}$ enzyme-linked immunosorbent assay [ELISA] test), lactoferrin (IBD-SCANTM ELISA test), the Hexagon OBTI (immunochromatographic test for detection of human hemoglobin), and LEUKO-TEST (lactoferrin latex-agglutination test) - were evaluated to discriminate irritable bowel syndrome (IBS) from IBD in a prospective study. ${ }^{40}$ Accuracy was similar with both fecal lactoferrin and fecal calprotectin assays ( $\sim 90 \%)$, but these tests do not differentiate between various types of inflammatory colitides (ie, diverticulitis, infectious or ischemic colitis). These findings have been 
replicated. ${ }^{36}$ Fecal calprotectin and lactoferrin outperform serum CRP or the clinical Crohn's disease activity index at correlating with endoscopic levels of inflammation (Spearman's $r=0.729$ and 0.773 , respectively; $P<0.001$ ), especially colonic inflammation. ${ }^{41}$ In clinical practice, these tests can be used to differentiate between IBD and IBS or to corroborate clinical flare-ups.

\section{CD-specific serologic and genetic markers Serologic markers in IBD: role of familial studies}

Subsets of IBD patients may have abnormal immune responses to various microbial antigens. ${ }^{42,43}$ Antibodies to Saccharomyces cerevisiae (ASCA) occur in $50 \%-70 \%$ of CD patients. ${ }^{44}$ The pathophysiological associations of seromarkers with IBD subtypes are supported by familial studies. Atypical antineutrophilic cytoplasmic antibodies (ANCA) are associated with ulcerative colitis (UC) in approximately $70 \%$ of patients, ${ }^{44}$ although familial studies do not suggest that ANCA has genetic underpinnings. Papo et $\mathrm{al}^{45}$ and Folwaczny et $\mathrm{a}^{46}$ both found no increase in ANCA prevalence among unaffected relatives of IBD patients $(\sim 3 \%-5 \%)$. Perinuclear ANCA (pANCA) was subsequently associated with Crohn's colitis. $^{47}$

In contrast, ASCA has shown strong familial associations, suggesting its primary role as a stable biomarker in $\mathrm{CD}$. Sendid et $\mathrm{al}^{48}$ found $20 \%$ of unaffected relatives were ASCApositive in $\mathrm{CD}$ families versus less than $1 \%$ of unaffected relatives in control families. A Belgian study also found similar results $(21 \%)^{49}$ but showed that ASCA is not associated with any alteration in intestinal permeability. An Italian study demonstrated elevated ASCA $(\sim 25 \%)$ in unaffected relatives of IBD patients, which included purely UC-affected families. ${ }^{50}$ These investigators concluded there may be a primary genetic influence on ASCA status in IBD families. The possible genetic underpinnings of ASCA in $\mathrm{CD}$ are complex. An IBD twin study found only a 5\% seroprevalence of ASCA among 20 unaffected (discordant) monozygotic twins with a CD sibling, versus $26 \%$ among 27 discordant dizygotic twins. This suggests the importance of shared environmental factors in familial CD. ${ }^{51}$ However, there still may be a genetic component to ASCA. Seibold et a ${ }^{52}$ showed that ASCA positivity is associated with mutations in the mannan-binding lectin $(M B L)$ gene that result in $M B L$ deficiency. The physiologic role of $M B L$ includes immune recognition of yeasts and other mannose-expressing pathogens. ${ }^{53} \mathrm{Hence}$, it may be that
ASCA seroreactivity occurs when such pathogens are able to penetrate a permeable intestinal barrier, especially in the setting of $M B L$ deficiency. ${ }^{53}$ Newer IBD markers (described below) have also shown increased familial expression, ${ }^{54}$ particularly for CD.

A natural question that follows from familial ASCA is whether ASCA presence positively predisposes to future CD development. The literature on this issue is sparse. One study of 102 ASCA-positive first-degree relatives of IBD patients revealed a less than $2 \%$ cumulative incidence of IBD over 7 years. ${ }^{55}$ In a nonfamilial study, Israeli et a ${ }^{56}$ found $31 \%$ ASCA seropositivity before $\mathrm{CD}$ diagnosis in military recruits. An additional $23 \%$ of $\mathrm{CD}$ patients seroconverted after $\mathrm{CD}$ diagnosis, and none of the 95 non-IBD controls were ASCA-positive over the same 38-month median follow-up. Prospective studies would be most informative in this regard.

\section{IBD diagnostics: serologic markers as a screening or diagnostic tool}

If seromarkers such as ASCA do precede CD development in as many as one-third of individuals, the positive predictive value (PPV) of the test becomes a relevant issue. Several recent studies have shed light on the spectrum of non-IBD diseases demonstrating ASCA phenomena (Table 1). ${ }^{57-65}$ Data for newer IBD markers are not yet available, and clinicians using serologic markers in the evaluation of IBD should be aware of this. ASCA was originally reported as an antibody to the nonpathogenic yeast $S$. cerevisiae in CD. ${ }^{43,66}$ However, the clinically relevant yeast Candida albicans also expresses ASCA epitopes under conditions favoring their virulence; a study from the ASCA-pioneering group in Lille, France, ${ }^{57}$ confirmed that $100 \%$ of patients with systemic candidiasis have acute ASCA titers above cutoff values considered significant in $\mathrm{CD}$. However, this does not preclude the role of ASCA in CD. Candida albicans may be of greater relevance to CD than S.cerevisiae, which has never been considered pathogenic in $\mathrm{CD}$. The same group $^{57}$ confirmed that C.albicans is an immunogen for ASCA in CD and is more prevalent in healthy relatives of patients with $\mathrm{CD} .{ }^{67}$ Bacterial infections and other chronic diseases may also generate ASCA positivity in some individuals (Table 1) ${ }^{58}$ Rates of $21 \%-44 \%$ seropositivity have been reported in cystic fibrosis. Bacterial infection was suspected of playing a role in this context. ${ }^{59,60}$ Intestinal tuberculosis, highly prevalent in many areas of the world, may be difficult to clinically or endoscopically distinguish from CD. ${ }^{68}$ Makharia et $\mathrm{al}^{61}$ reported seropositivity rates of $43 \%$ for immunoglobulin A (IgA) and $47 \%$ for ASCA 
Table I Seroprevalence of ASCA positivity, IgA and IgG in non-IBD disease

\begin{tabular}{|c|c|c|c|c|c|}
\hline Disease & ELISA assay & $\begin{array}{l}\text { ASCA } \\
\text { IgA }\end{array}$ & $\begin{array}{l}\text { ASCA } \\
\text { IgG }\end{array}$ & $\begin{array}{l}\text { ASCA } \\
\text { IgA or IgG }\end{array}$ & Study \\
\hline Systemic candidiasis & Lille assay, inhouse & - & - & $100 \%$ & Standaert-Vitse et al ${ }^{57}$ \\
\hline Various acute bacterial infections & Aesku Diagnostics, Germany & - & - & $22 \%$ & Berlin et al ${ }^{58}$ \\
\hline Cystic fibrosis, pediatric & Quanta-Lite, Inova Diagnostics, USA & $13 \%$ & $11 \%$ & $21 \%$ & Condino et $\mathrm{al}^{59}$ \\
\hline Cystic fibrosis, adult & Quanta-Lite, Inova Diagnostics, USA & $44 \%$ & - & - & Lachenal et al ${ }^{60}$ \\
\hline Intestinal tuberculosis & Aesku Diagnostics, Germany & $43 \%$ & $47 \%$ & $67 \%$ & Makharia et $a^{61}$ \\
\hline Celiac disease (pre-treatment) & Quanta-Lite, Inova Diagnostics, USA & $20 \%$ & $54 \%$ & $59 \%$ & Granito et $\mathrm{al}^{62}$ \\
\hline Type I diabetes mellitus & Orgentec, Germany & $10 \%$ & $21 \%$ & $25 \%$ & Sakly et $\mathrm{al}^{63}$ \\
\hline Primary biliary cirrhosis & Quanta-Lite, Inova Diagnostics, USA & $19 \%$ & $11 \%$ & $23 \%$ & Muratori et al ${ }^{64}$ \\
\hline Primary sclerosing cholangitis & Quanta-Lite, Inova Diagnostics, USA & $32 \%$ & $28 \%$ & $44 \%$ & Muratori et al ${ }^{64}$ \\
\hline Autoimmune hepatitis & Quanta-Lite, Inova Diagnostics, USA & $12 \%$ & $16 \%$ & $18 \%$ & Muratori et al ${ }^{64}$ \\
\hline Ankylosing spondylitis & Quanta-Lite, Inova Diagnostics, USA & $23 \%$ & $12 \%$ & - & Riente et $\mathrm{al}^{65}$ \\
\hline Rheumatoid arthritis & Quanta-Lite, Inova Diagnostics, USA & $18 \%$ & $10 \%$ & - & Riente et al ${ }^{65}$ \\
\hline
\end{tabular}

Abbreviations: ASCA, antibodies to Saccharomyces cerevisiae; ELISA, enzyme-linked immunosorbent assay; IBD, inflammatory bowel disease; IgA, immunoglobulin A; IgG, immunoglobulin $\mathrm{G}$.

in Indian patients with intestinal tuberculosis, rates that did not differ from those in CD patients. Noninfectious diseases considered in a differential diagnosis of IBD may also demonstrate ASCA phenomena. For example, ASCA titers may be elevated in untreated celiac disease and disappear completely after introducing a gluten-free diet. This suggests that abnormal intestinal permeability plays an important role in ASCA generation, as well as for other antibodies in celiac disease. ${ }^{62}$ ASCA positivity may also reflect a phenotypic continuum between ulcerative jejunitis, celiac disease, and classical CD. Occasionally, clinicians will encounter patients with IBD or suspected IBD, or with associated diseases such as ankylosing spondylitis or rheumatoid arthritis. In these settings, ASCA has been shown to be nonpredictive of occult IBD. ${ }^{69}$ In addition, pANCA has been associated with autoimmune hepatitis (AIH) type 1, particularly in men and in those AIH-1 patients with smooth muscle antibody of the anti-actin type. ${ }^{70}$ Therefore, caution is required when interpreting positive tests in such patients, particularly those without gastrointestinal symptoms. Testing for ASCA alone may have limited usefulness in predicting CD. Furthermore, there is clinical overlap of ASCA in UC.

These limitations have led to the development of serologic marker combinations in panels to increase their predictive values (Table 2). ${ }^{71-76}$ Sandborn and colleagues ${ }^{77}$ reported a PPV of $86 \%$ for CD with the ASCA-positive/ANCA-negative combination. Similarly, Peeters et $\mathrm{al}^{78}$ reported a PPV of $91 \%$ for this combination. The predictive value is increased by testing ASCA for both IgA and IgG (immunoglobulin G) subfractions. ${ }^{79}$ However, a meta-analysis of more than 60 ASCA and ANCA studies in IBD $^{80}$ showed a modest overall sensitivity of the ASCA-positive/ANCA-negative combination for CD (55\%) (Table 2). ${ }^{44,78,80-86}$ Several novel bacterial antigens in CD have been identified as potentially useful in serologic testing. Approximately 55\% of CD patients test positive for antibodies to Escherichia coli outer membrane porin $\mathrm{C}$ (anti-OmpC) ${ }^{87}$ and for antibodies to a bacterial sequence derived from Pseudomonas fluorescens (anti-I2). Reactivity to CBir1 flagellin, a colitogenic antigen of the enteric flora in $\mathrm{C} 3 \mathrm{H} / \mathrm{HeJBir}$ mice strain, is highly prevalent $(50 \%)$ in $\mathrm{CD} .{ }^{88}$ In addition, anti-CBir1 is detected in patients who are nonreactive to the ASCA, OmpC, I2, and ANCA antigens. ${ }^{89}$ Recently, a class of antibodies called antiglycans have been shown to be prevalent in CD. ${ }^{90}$ These homogeneous antibodies are directed against carbohydrate moieties on cell surfaces of erythrocytes, immune cells, and microorganisms. ${ }^{90}$

Investigators have sought to define specific patterns of reactivity with serologic biomarkers. Such patterns may better distinguish CD from UC or further characterize patients with indeterminate colitis, possibly into a CD or UC diagnosis. Computer algorithm modeling of clinical pattern recognition has been developed to facilitate pattern recognition. ${ }^{80,87,91}$ For example, the presence of anti-CBir1 and pANCA antibodies among CD patients can help to distinguish between UC and a UC-like CD phenotype. ${ }^{89}$ In addition, when combined with ASCA and pANCA testing, anti-OmpC and anti-I2 antibodies can help identify up to $84 \%$ of patients with $C D$; this yield drops to $54 \%$ when ASCA is considered alone. ${ }^{87}$

\section{IBD prognostics: individual serologic markers and CD disease behavior}

While initially used for diagnostic purposes, serologic panels are more useful in clinical practice for their prognostic information. While each serologic marker is associated with some form(s) of complicated disease behavior, a qualitative 
Table 2 Summary of seromarker characteristics in IBD

\begin{tabular}{|c|c|c|c|}
\hline Seromarker & Antigenic determinant & Disease indication & $\begin{array}{l}\text { Sensitivity, specificity, } \\
\text { PPV, NPV }\end{array}$ \\
\hline ASCA & $\begin{array}{l}\text { Mannose residue forms the } \\
\text { phosphopeptidomannan of the cell } \\
\text { wall of Saccharomyces cerevisiae; } \\
\text { also expressed by Candida albicans }\end{array}$ & $\begin{array}{l}\text { CD } \\
\text { - Sensitivity for CD improved when } \\
\text { used in combination with PANCA }\end{array}$ & $\begin{array}{l}\text { Sensitivity: } 53 \%^{80} \\
\text { Specificity: } 89 \%^{80} \\
\text { PPV: } 73 \%^{\mathrm{a}, 81} \\
\text { PPV: } 84 \% \text { with (-) PANCA } \\
\text { NPV: } 68 \%^{78}\end{array}$ \\
\hline pANCA & $\begin{array}{l}\text { Unidentified protein of the nuclear } \\
\text { envelope of neutrophils }\end{array}$ & $\begin{array}{l}\text { UC } \\
\text { - May be }(+) \text { in CD with UC-like phenotype } \\
\text { - May predict chronic pouchitis } \\
\text { following IPAA }\end{array}$ & $\begin{array}{l}\text { Sensitivity: } 55 \%^{80} \\
\text { Specificity: } 89 \%^{80} \\
\text { PPV: } 82 \% \text { a,81 } \\
\text { NPV: } 89 \%^{78}\end{array}$ \\
\hline Anti-OmpC & $\begin{array}{l}\text { Outer membrane porin, originally } \\
\text { isolated from Escherichia colis7 }\end{array}$ & $\begin{array}{l}\text { CD } \\
\text { - May identify CD in up to } 15 \% \\
\text { of ASCA (-) patients }\end{array}$ & $\begin{array}{l}\text { Sensitivity: } 20 \%-55 \%^{44} \\
\text { Specificity: } 89 \%^{44} \\
\text { PPV: } 83.4 \% \text { b,82 } \\
\text { NPV: } 25.3^{\mathrm{b}, 82}\end{array}$ \\
\hline Anti-12 & $\begin{array}{l}\text { Bacterial sequence derived } \\
\text { from Pseudomonas fluorescens }\end{array}$ & $C D$ & $\begin{array}{l}\text { Sensitivity: } 42 \%^{44} \\
\text { Specificity: } 76 \%^{44} \\
\text { PPV: } 96 \%^{c, 83} \\
\text { NPV: } 26 \%^{\ddagger}, 83\end{array}$ \\
\hline Anti-CBirl & Flagellin, CBir (Clostridium subphylum) & $\begin{array}{l}\text { CD } \\
\text { - May help to differentiate CD } \\
\text { from UC in pANCA (+) patients }\end{array}$ & $\begin{array}{l}\text { Sensitivity: } 50 \%, 84 \\
\text { Specificity: } 53 \% c, 84 \\
\text { PPV: } 45 \% c, 85 \\
\text { NPV: not reported }\end{array}$ \\
\hline $\begin{array}{l}\text { Combination seromarker } \\
\text { panel (Prometheus IBD } \\
\text { Serology - 7) }\end{array}$ & $\begin{array}{l}\text { ASCA (IgA, } \lg G) \text {, anti-OmpC, anti-CBir I, } \\
\text { NSNA with IFA perinuclear pattern and } \\
\text { DNAse sensitivity }\end{array}$ & $\begin{array}{l}\text { Differentiating IBD from non-IBD, } \\
\text { and } C D \text { from UC }\end{array}$ & $\begin{array}{l}\text { Sensitivity: } 80 \%^{86} \\
\text { Specificity: } 61.5 \%^{86} \\
\text { PPV: } 68 \%^{86} \\
\text { NPV: } 75 \%^{86}\end{array}$ \\
\hline
\end{tabular}

Notes: aValue reported for distinguishing CD from UC; bUsing expanded-spectrum IgA antibody to multiple outer membrane porins (Omp); ${ }^{\mathrm{C} E x c l u s i v e ~ p e d i a t r i c ~ c o h o r t . ~}$ Abbreviations: ASCA, antibodies to Saccharomyces cerevisiae; CD, Crohn's disease; IBD, inflammatory bowel disease; IFA, indirect fluorescent-antibody assay; IgA, immunoglobulin A; IPAA, ileal pouch-anal anastomosis; NPV, negative predictive value; NSNA, neutrophil-specific nuclear auto-antibodies; OmpC, outer membrane porin C; PANCA, perinuclear ANCA; PPV, positive predictive value; UC, ulcerative colitis.

response to multiple markers is more predictive of a severe course in CD. Studies in CD have correlated ASCA reactivity with increased risk of surgery within 3 years of diagnosis, ${ }^{92}$ small bowel disease location, ${ }^{93}$ early age at diagnosis, and a complicated disease course. ${ }^{94}$ Additional CD studies have linked pANCA levels to UC-like disease behavior ${ }^{47,94}$ and a lack of fibrostenosing/penetrating disease. ${ }^{93,94}$ In UC patients undergoing ileal pouch anal anastomosis, high levels of pANCA before proctocolectomy are associated with development of chronic pouchitis. ${ }^{95,96}$ The next generation of serologic markers after ASCA and pANCA have been associated with an aggressive disease course in CD (Table 3). Anti-OmpC and anti-I2 are associated with fibrostenosing and internal-perforating disease behavior as well as small bowel surgery. ${ }^{50,71,73}$ Additionally, multivariate logistic regression analysis has shown that these two markers are independently associated with a complicated CD phenotype and/or surgery. ${ }^{71}$ Patients who express anti-CBir1 are nearly twice as likely to develop small bowel disease and complicated phenotypes such as fibrostenosis and internal-perforating disease.$^{89} \mathrm{~A}$ recent study reported that anti-CBirl can be predictive of the development of pouchitis after ileal pouch anal anastomosis in pANCA-positive patients. ${ }^{96}$

\section{Serologic panels and disease behavior}

An association between severe, complicated CD and highlevel immune responses was confirmed in multiple studies analyzing quantitative antibody levels in panels of serologic markers (Table 3). In 2004, Mow et $\mathrm{al}^{71}$ associated cumulative antibody responses to I 2 and $\mathrm{OmpC}$ with distinct disease phenotypes. Sera from $303 \mathrm{CD}$ patients were analyzed for anti-I2, anti-OmpC, and ASCA. Quartile scores of 1-4 were assigned to the individual antigens based on antibody levels measured; a quartile sum score (range 3-12) was derived for each patient to represent the cumulative quantitative immune response to all four antigens. ${ }^{71}$ Patients with a qualitative antigen reactivity to $\mathrm{I} 2, \mathrm{OmpC}$, and oligomannan (ASCA) were more likely to develop complicated disease (fibrostenosing and internal-perforating disease) and require small bowel surgery than patients expressing fewer than three antibodies $(P \leq 0.001) .{ }^{71}$ Quartile sum score analysis suggested that the magnitude of antibody responses to $\mathrm{I} 2$, OmpC, 
Table 3 Studies of serologic panels in predicting disease phenotype in Crohn's disease

\begin{tabular}{|c|c|c|c|c|c|c|}
\hline Study & Year & Design & Population & $\mathbf{N}$ & $\begin{array}{l}\text { Serologic } \\
\text { markers }^{\mathrm{a}}\end{array}$ & Key findings \\
\hline Mow et $\mathrm{a}^{71}$ & 2004 & Retrospective & Adult & 303 & $\begin{array}{l}\text { ASCA, anti-OmpC, } \\
\text { anti-12 }\end{array}$ & $\begin{array}{l}\text { - Anti-I2, anti-OmpC, and ASCA were each individually } \\
\text { associated with IP/S disease or small bowel surgery } \\
\text { - Patients seropositive for anti-I2, anti-OmpC, and ASCA } \\
\text { were more likely to develop complicated disease } \\
\text { behavior than those with reactivity to } 2,1 \text {, or } 0 \\
\text { markers ( } P \leq 0.00 \mathrm{I}) \\
\text { - Percentage of patients with complicated disease increased } \\
\text { with increasing magnitude of antibody response }\end{array}$ \\
\hline Arnott et $\mathrm{al}^{72}$ & 2004 & Retrospective & Adult & 142 & $\begin{array}{l}\text { ASCA, anti-OmpC, } \\
\text { anti-12 }\end{array}$ & $\begin{array}{l}\text { Presence and magnitude of responses associated with } \\
\text { small bowel disease }(P=0.02) \text {, disease progression } \\
(P<0.00 \mathrm{I}) \text {, perforating disease }(P=0.008) \text {, and } \\
\text { surgery }(P<0.00 \mathrm{I})\end{array}$ \\
\hline Papadakis et a ${ }^{73}$ & 2007 & Retrospective & Adult & 731 & $\begin{array}{l}\text { ASCA, anti-OmpC, } \\
\text { anti-I2, anti-CBir I }\end{array}$ & $\begin{array}{l}\text { - Confirmed that anti-CBirl is independently associated } \\
\text { with complicated CD phenotype }(P=0.0004) \\
\text { - Proportion of patients with IP/S disease increased with } \\
\text { increasing reactivity to all } 4 \text { antigens } \\
\text { - Addition of anti-CBir I reactivity enhanced } \\
\text { discrimination of CD phenotypes, particularly } \\
\text { complicated disease (IP/S), small bowel involvement, } \\
\text { and UC-like disease }\end{array}$ \\
\hline Dubinsky et al $7^{74}$ & 2006 & Prospective & Pediatric & 196 & $\begin{array}{l}\text { ASCA, anti-OmpC, } \\
\text { anti-I2, anti-CBirl }\end{array}$ & $\begin{array}{l}\text { - Anti-OmpC }(P=0.0006) \text { and anti-I2 }(P=0.0034) \text { were } \\
\text { associated with IP/S disease } \\
\text { - Frequency of IP/S disease increased with increasing } \\
\text { number of immune responses }(P=0.002) \\
\text { - OR of developing IP/S disease was highest among } \\
\text { children with all } 4 \text { immune markers (OR II.0; 95\% } \\
\text { Cl I.5-80.4; } P=0.03)\end{array}$ \\
\hline Dubinsky et a $\mathrm{l}^{75}$ & 2008 & $\begin{array}{l}\text { Prospective, } \\
\text { longitudinal }\end{array}$ & Pediatric & 796 & $\begin{array}{l}\text { ASCA, anti-OmpC, } \\
\text { anti-CBirl }\end{array}$ & $\begin{array}{l}\text { - Frequency of IP/S disease and surgery increased } \\
\text { significantly with both the number of immune responses } \\
(P<0.000 \mathrm{I}) \text { and magnitude of responses }(P<0.000 \mathrm{I}) \\
\text { - Immune reactivity to OmPC and } \mathrm{CBir} I \text { and presence } \\
\text { of ASCA were associated with faster progression to } \\
\text { complicated disease and surgery, significantly faster } \\
\text { than reactivity to I or } 2 \text { antigens }(P<0.000 \mathrm{I}) \\
\text { - The magnitude of immune response also influences faster } \\
\text { progression to complicated disease and surgery }(P<0.000 \mathrm{I})\end{array}$ \\
\hline Ippoliti et al $\left.\right|^{\mathrm{b}, 76}$ & 2009 & Retrospective & $\begin{array}{l}\text { Adolescent } \\
\text { and adult }\end{array}$ & 731 & $\begin{array}{l}\text { ASCA, CBirl, } \\
\text { OmpC, } \\
\text { I2, NOD2 }\end{array}$ & $\begin{array}{l}\text { - NOD2 was associated with small bowel disease } \\
\text { involvement }(P<0.00 \mathrm{I}) \text {, fibrostenosing phenotype } \\
(P<0.000 \mathrm{I}) \text {, history of small bowel surgery }(P<0.05) \text {, } \\
\text { and inversely with UC-like phenotype }(P<0.0 \mathrm{I}) \\
\text { - The prevalence of fibrostenosis was significantly associated } \\
\text { with the number of positive antibodies as well as QSS } \\
\text { - With combined serologic reactivity and NOD2 status, } \\
\text { ORs for developing fibrostenotic disease were greater } \\
\text { with presence of NOD2 variants and also increased } \\
\text { with higher QSS }\end{array}$ \\
\hline
\end{tabular}

Notes: ${ }^{a} \mathrm{pANCA}$ was measured in some studies but not calculated with the antibodies to determine cumulative association with aggressive disease; ${ }^{\mathrm{l}} \mathrm{Pp}$ (iti et al studied $\mathrm{CD}$ patients' seroreactivity and their NOD2 status.

Abbreviations: ASCA, antibodies to Saccharomyces cerevisiae; CD, Crohn's disease; CI, confidence interval; IP/S, internal-penetrating/stricturing disease; NOD2, nucleotide oligomerization domain 2; OmpC, outer membrane porin C; OR, odds ratio; QSS, quartile sum score; UC, ulcerative colitis.

and oligomannan was also associated with complicated small bowel disease (Figure 2). ${ }^{71}$ In a similar study, Arnott et al also found that the presence and magnitude of anti-OmpC, anti-I2, and ASCA were significantly associated with complicated disease (Table 3). ${ }^{72}$ Papadakis et $\mathrm{al}^{73}$ examined a serologic panel that included anti-CBir1 in addition to ASCA, anti-I2, and anti-OmpC to predict disease severity in 731 patients with CD. Quartile sum scores for this cohort revealed that increasing levels of reactivity to all four antigens were associated with fibrostenosing and internal-perforating disease. ${ }^{73}$ 


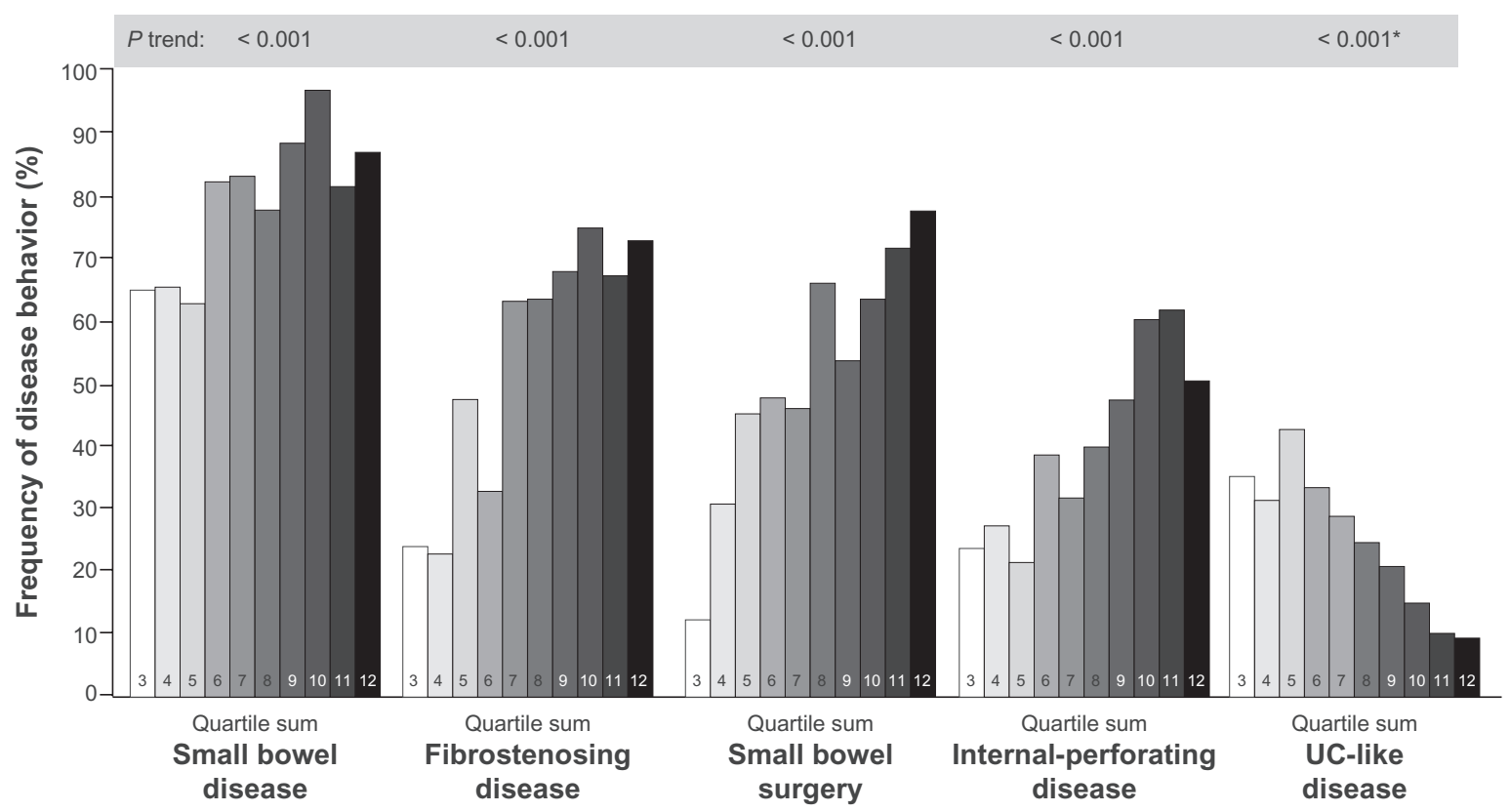

Figure 2 Frequency of complicated small bowel disease, as represented by antibody quartile sum score. A summation score of 3-12 for antibody titers toward I2, OmpC, and ASCA was calculated and categorized into quartiles (QSS). Patients with higher sum scores had greater frequency of complicated course (fibrostenosing, penetrating, or small bowel disease, or need for surgery).

Note: *Denotes negative $P$ trend.

Copyright (C) 2008, Elsevier. Reproduced with permission from Mow et al. ${ }^{71}$

Abbreviations: ASCA, antibodies to Saccharomyces cerevisiae; OmpC, outer membrane porin C; QSS, quartile sum score; UC, ulcerative colitis.

When added to the quantitative responses to the other three antigens, anti-CBir1 reactivity enhanced the discrimination of complicated disease phenotypes (fibrostenosing or internal penetrating), small bowel involvement, and UC-like behavior. ${ }^{73}$ Dubinsky et a $7^{74,75}$ conducted the first two prospective studies in pediatric CD patients that demonstrated a relationship between serologic responses and aggressive disease behavior. In the first study in 196 patients tested for anti-I2, anti-OmpC, ASCA, and anti-CBir1, the frequency of complicated disease behavior increased as the number of immune responses increased; the presence of four positive markers was associated with the highest likelihood of aggressive disease (Table 3). ${ }^{74}$ These initial findings were confirmed in another, larger study of 796 pediatric CD patients using ASCA, anti-OmpC, and anti-CBir $1 .{ }^{75}$ The frequency of internal-penetrating disease, stricturing disease, and surgery increased substantially with both the number and magnitude of immune responses. ${ }^{75}$ Kaplan-Meier estimates for time to development of internal-penetrating/stricturing disease and CD-related surgery by quartile sum scores are presented in Figure $3 .^{75}$ In both instances, time to adverse outcome (complex disease, surgery) is generally shorter in those patients with the highest quartile scores, whereas those in the lowest quartile have a very high probability of remaining free of adverse outcomes over long periods. The prospective design of these studies supports the use of serologic testing to predict future disease behavior. ${ }^{74,75}$

\section{Future directions Genetic markers in assessing aggressive disease behavior}

The identification of genetic markers in $\mathrm{CD}$ is an active area of research. ${ }^{7,71,97-101}$ The nucleotide oligomerization domain 2 (NOD2), also known as caspase-activating recruitment domain 15 (CARD15) at the IBD1 locus is the first major susceptibility gene described for $\mathrm{CD} .{ }^{102-104}$ Three major-effect NOD2/CARD15 variants have been found to account for the majority (81\%) of over 30 such allelic mutations in CD; the mutations R702W, G908R, and 1007fs being designated as single nucleotide polymorphisms (SNPs) 8, 12, and 13, respectively. ${ }^{100,102}$ Data from across the general population suggest a low penetrance for NOD2/CARD15 mutations. However, among CD patients, each of the three SNPs has been shown to be independently associated with development of symptoms, with the greatest risk conferred by the SNP13 mutant allele and in those with multiple mutations. ${ }^{104-106}$ The NOD2/ CARD15 variant genotypes have been associated with severe CD phenotypes. ${ }^{97,98,100,101,107,108}$ Abreu et a ${ }^{97}$ compared NOD2/ CARD15 genotypes to serum immune markers, disease behavior, and disease location in two consecutive cohorts of 

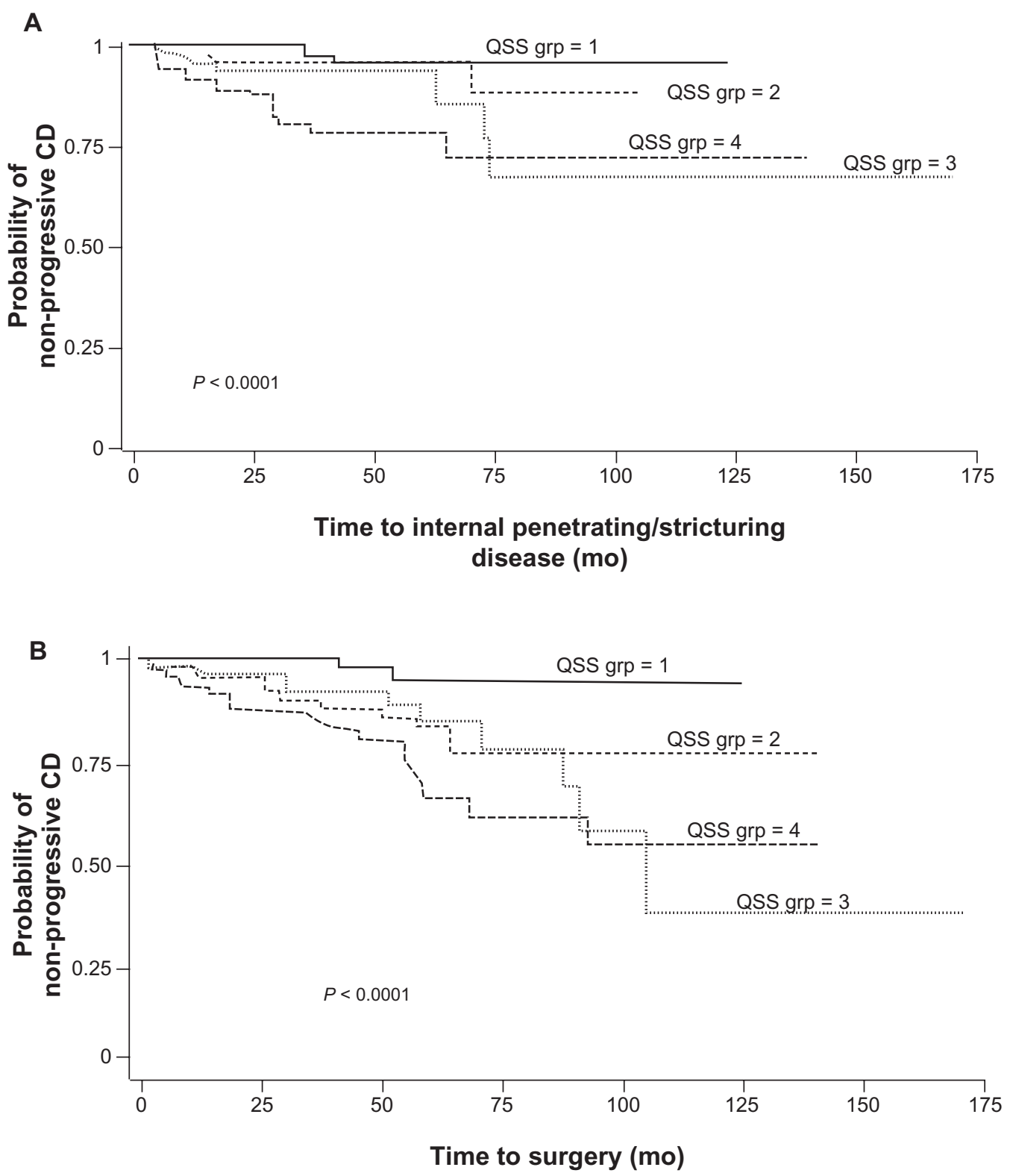

Figure 3 Kaplan-Meier plot estimates for internal-penetrating/stricturing disease and need for bowel surgery by QSS of antibody titers toward I2, OmpC, and ASCA among $\mathrm{CD}$ patients. The figure depicts a higher probability of maintaining a simple, noncomplicated disease course during prospective follow-up, among those patients who fall into the lower QSS groups (QSS groups I and 2) (A). Conversely, half of the patients in QSS group 3 required surgery within 100 months of follow-up (B). Copyright $@ 2008$, Elsevier. Reproduced with permission from Dubinsky et al. ${ }^{75}$

Abbreviations: ASCA, antibodies to Saccharomyces cerevisiae; CD, Crohn's disease; OmpC, outer membrane porin C; QSS, quartile sum score.

CD patients (Table 4). Multivariate analysis showed a significant association between the NOD2/CARD15 variants and fibrostenosing disease (OR 2.8; 95\% CI 1.3-6.0; $P=0.011$ ) ${ }^{97}$ In addition, the risk of developing fibrostenosing disease was greatest among carriers of two mutations (OR 7.4; 95\% CI 1.9-28.9; $P=0.004)$. Similar findings have been observed in large European ${ }^{100,107}$ and American ${ }^{71,98}$ cohorts.

Genome-wide association studies have identified approximately $71 \mathrm{CD}$-associated gene susceptibility loci, with potentially many more genes. ${ }^{104}$ Some of these have been assessed for their relationship to $\mathrm{CD}$ phenotype and disease course. Weersma et a ${ }^{109}$ examined genetic variants, including NOD2/CARD15, Drosophilia discs homolog 5 (DRG5), autophagy-related 16-like 1 gene (ATG16L1), and the interleukin 23 receptor gene $(I L 23 R)$. Results showed that an increase in the number of allelic variants or genotypes was associated with an increased risk of developing $\mathrm{CD}$ and having a complicated disease course. ${ }^{109}$ These findings suggest that it is possible to assess a given patient's genetic profile to determine risk of complicated disease. 
Table 4 Significant individual associations of antibody responses and NOD2/CARD/5 genotype with Crohn's disease phenotypes ${ }^{71,89,97}$

\begin{tabular}{|c|c|c|c|c|}
\hline \multirow[t]{2}{*}{ Marker } & \multicolumn{4}{|c|}{ Significant individual associations } \\
\hline & $\begin{array}{l}\text { Small bowel } \\
\text { involvement }\end{array}$ & $\begin{array}{l}\text { Complicated } \\
\text { CD phenotype }\end{array}$ & $\begin{array}{l}\text { Small bowel } \\
\text { surgery }\end{array}$ & $\begin{array}{l}\text { UC-like } \\
\text { behavior }\end{array}$ \\
\hline ASCA & Yes & Yes & Yes & Yes (negative) \\
\hline pANCA & Yes (negative) & Yes (negative) & Yes (negative) & Yes \\
\hline Anti-12 & No & Yes & Yes & No \\
\hline Anti-OmpC & No & Yes & Yes & No \\
\hline Anti-CBirl & Yes & Yes & No & No \\
\hline NOD $2^{\mathrm{b}}$ & Yes & Yes & No & Yes (negative) \\
\hline
\end{tabular}

Notes: a Complicated CD phenotypes include fibrostenosing or internal-perforating disease; ${ }^{\mathrm{N} O D} 2$ is a CD susceptibility gene.

Abbreviations: ASCA, antibodies to Saccharomyces cerevisiae; CARD I5, Caspase-activating recruitment domain I5; CD, Crohn's disease; NOD2, nucleotide oligomerization domain 2; OmpC, outer membrane porin C; PANCA, perinuclear ANCA; UC, ulcerative colitis.

\section{Synergism between serologic phenotypes and genetic variants}

Emerging data from studies of familial expression of ASCA, anti-OmpC, and other IBD serologic markers suggest that genetic mutations lead to alterations in the expression of antibodies to microbial antigens. ${ }^{49,54,99,101,110-112}$ Anti-CBir1 and ASCA expression were linked to $N F K B 1$ haplotypes and subsequently to reductions in $N F-k B$ activation, thus describing another link between innate and adaptive immunity in IBD. ${ }^{113}$ Studies have not always concurred regarding the association between NOD2/CARD15 polymorphisms and seromarkers in IBD. ${ }^{99,110,114}$ However, NOD2/CARD15 variants seem to be more common in patients testing positive for multiple serologic markers, including those with high antibody levels (elevated quartile sum scores) (Figure 4). ${ }^{101,111}$ Ippoliti et al ${ }^{76}$ determined that a combination of altered innate and adaptive immune responses act synergistically to increase the development of complicated CD, particularly fibrostenosing disease. After grouping patients by serologic quartile sum scores of 4-6, 7-9, 10-13, and 14-16 and subdividing by the presence or absence of NOD2/CARD15, they calculated ORs for developing fibrostenotic disease (Table 5). The ORs were significantly greater among patients with the presence of NOD2 variants than those without. The ORs were also increased with higher quartile sum scores.

Future diagnostic tests may quantitatively assign a risk probability for severe disease by using algorithms that analyze these serologic and genetic biomarkers. A new CD prognostic test was recently made available. This serogenetic panel is composed of seven assays for nine markers, including six serologic biomarkers, specifically ASCA-IgA, ASCA-IgG, anti-OmpC, anti-I2, anti-CBir1, and pANCA. In addition, the test recognizes three NOD2 gene variants (SNP8, SNP12, and SNP13). The prognostic panel calculates

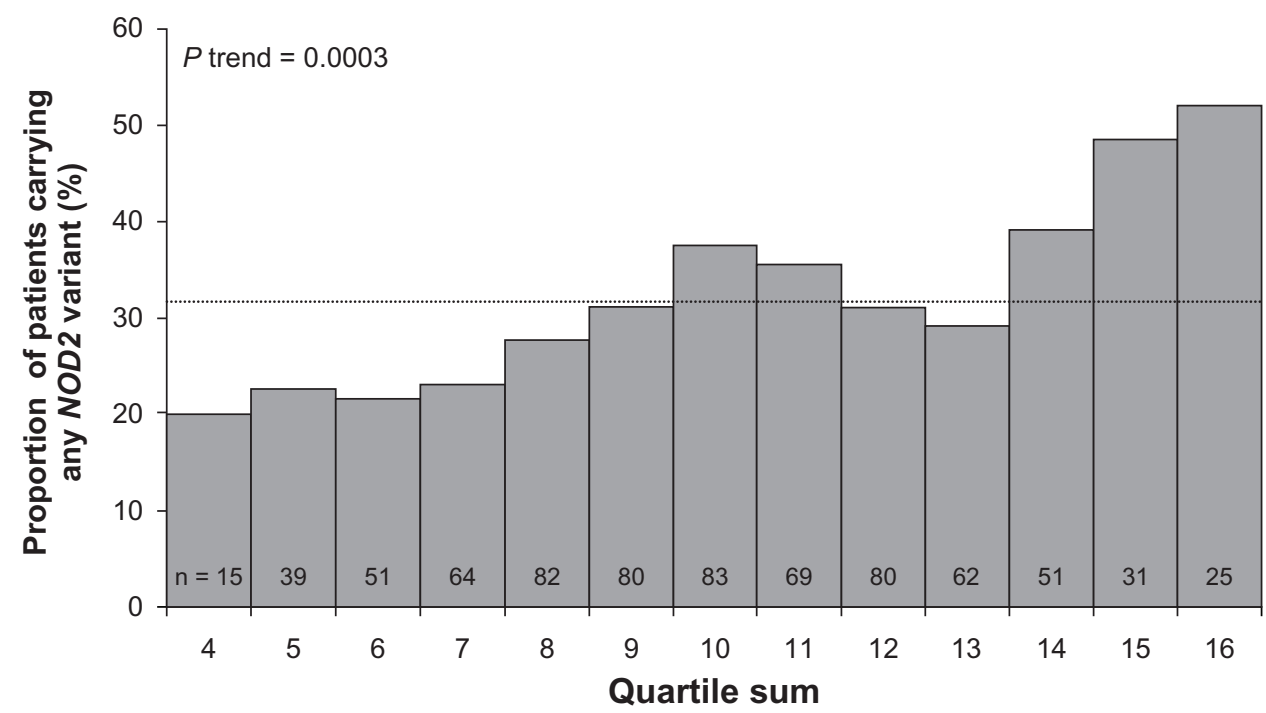

Figure 4 Frequency of carriage of NOD2/CARDI5 variant relative to semiquantitative antibody reactivity, as represented by quartile sum (range 4-16). The dotted line represents the mean $31.8 \%$ frequency of carriage of at least one NOD2/CARD 15 variant, across the entire cohort. Copyright @ 2007 , Elsevier. Reproduced with permission from Devlin et al."'I

Abbreviations: NOD2, nucleotide oligomerization domain 2; CARDI5, caspase-activating recruitment domain 15. 
Table 5 Demonstration of synergism between NOD2 variants and antibody levels in fibrostenosis

\begin{tabular}{llll}
\hline Quartile & $\begin{array}{l}\text { Presence of } \\
\text { NOD2 variant? }\end{array}$ & $\begin{array}{l}\text { Odds ratio } \\
\text { (confidence limits) }\end{array}$ & P value \\
\hline $4-6$ & No & Reference & Reference \\
& Yes & $0.2(0-1.2)$ & \\
$7-9$ & No & $1.2(0.6-2.2)$ & 0.004 \\
& Yes & $2.7(1.3-5.5)$ & \\
$10-13$ & No & $3.3(1.8-6.0)$ & 0.003 \\
& Yes & $7.3(3.7-14.4)$ & \\
$14-16$ & No & $4.8(2.3-10.1)$ & 0.01 \\
& Yes & $9.6(4.2-21.8)$ & \\
\hline
\end{tabular}

Copyright (c) 2010, John Wiley \& Sons, Inc. Reproduced with permission from Ippoliti et al. ${ }^{76}$

Abbreviation: NOD2, nucleotide oligomerization domain 2.

probability of complications curve based on antibody quartile sum scores and NOD2/CARD15 mutation status. The results are then analyzed by a logistic regression algorithm to quantify the likelihood that a patient will progress to a complicated $\mathrm{CD}$ phenotype. The test output is a probability score reflecting the likelihood of disease progression to complications. ${ }^{115}$

\section{Current research in identifying predictors of treatment response}

Another area of growing interest that has potential to contribute to a personalized approach in $\mathrm{CD}$ is the prediction of response to medical therapies, particularly biologic agents. ${ }^{116,117}$ Some clinical features have been shown to influence response to infliximab. In a prospective study in $74 \mathrm{CD}$ patients, Arnott et al ${ }^{116}$ found that smoking significantly influences response to infliximab, with smokers less likely to respond at 4 weeks (OR $0.24 ; 95 \%$ CI $0.06-0.91$; $P=0.035$ ) and more likely to relapse at 1 year (relative risk 3.2; $P=0.0026$ ) than nonsmokers. Other factors that had predictive value were colonic disease, which increased the likelihood of response at 4 weeks nearly five-fold, and concomitant immunosuppression, which was associated with reduced risk of relapse at 1 year. ${ }^{116}$ In addition, detectable trough serum concentrations of infliximab (irrespective of antibody formation) have been shown to be associated with higher rates of clinical and endoscopic remission. ${ }^{117}$ Investigators have begun to explore the relationship of various serologic markers with response to medical therapies. Sandborn et $\mathrm{al}^{118}$ found an increased frequency of pANCA positivity in patients with left-sided UC that was resistant to oral and rectal 5-aminosalicylates and corticosteroids. In 2004, Mow et $\mathrm{al}^{119}$ reported the results of a small pilot study that suggested serum reactivity to microbial antigens, particularly to OmpC and I2, would help to predict response to combination antibiotic therapy. Finally, the utility of serologic markers in predicting response to biologic agents was explored, with one study demonstrating an insignificant trend toward lower response rates to infliximab with the pANCA-positive/ ASCA-negative combination in $\mathrm{CD}^{120}$ and another associating the same combination with suboptimal early clinical response to infliximab in UC (OR 0.40; 95\% CI 0.16-1.00; $P=0.049) .{ }^{121}$ Investigators developed an algorithm to predict response to infliximab using a previous cohort of 287 patients with inflammatory or fistulizing $\mathrm{CD}$ and combining key clinical predictors (ie, age $<40$ years, concurrent use of immunosuppressants, disease location, and CRP levels) and pharmacogenetic data of three apoptotic SNPs (Fas ligand-843 C/T, Fas-670 G/A, and Caspase9 93 C/T). ${ }^{122}$ The algorithm for inflammatory disease enabled prediction of response rates of $21.4 \%-100 \%$ and remission rates of $15.8 \%-85.7 \%$, while the algorithm for fistulizing disease enabled prediction of response rates of $46.6 \%-100 \%$ and remission rates of $20 \%-57.6 \%{ }^{122}$ Recently, Dubinsky et al ${ }^{123}$ indicated that a combination of a phenotype, serotype, and genotype is the best predictive model of nonresponse to anti-TNF- $\alpha$ agents in pediatric patients. Specifically, the most predictive model included the presence of three novel "pharmacogenetic" loci, the IBD-associated loci BRWD1, pANCA, and a UC diagnosis $(P<0.05$ for all). The relative risk of nonresponse increased 15 times as the number of risk factors increased from $0-2$ to $\geq 3(P<0.0001) .{ }^{123}$

\section{Impact of predictive factors}

Current evidence suggests that a combination of clinical findings (eg, smoking) and the measurement of immune responses with serologic testing - in combination with genetic testing - can help to predict disease behavior. ${ }^{124}$ Moreover, evidence shows that these tools may be used to stratify patients at the time of diagnosis on the basis of their risk of developing aggressive disease. ${ }^{124}$ Screening for NOD2/CARD15 genetic variants early in the patient's disease course may also provide additional evidence to suggest a patient's likelihood of disease progression and allow clinicians to tailor therapeutic strategies based on the aggressiveness of IBD subtype. ${ }^{124}$ Early aggressive intervention would then be delivered to high-risk patients and less intensive therapies to those more likely to have a benign disease course. While serogenetic testing for diagnosing disease, predicting disease course, or determining treatment options $^{5}$ is not routinely used, clinical practice guidelines may ultimately evolve to include a therapeutic algorithm recommending use of top-down therapy in patients with or 
at risk for complicated disease behavior, as assessed by the combination of clinical characteristics and serologic and genetic findings. ${ }^{11}$ Furthermore, the identification of new pathogenetic treatments, including cytokines (eg, IL-23, IL-17), diapedesis inhibitors (eg, natalizumab, vedolizamab), and chemokine receptor antagonists (eg, CCX282-B), offer the promise of targeted biologic therapies. Future generations of IBD serologic profiles/genetic testing can be anticipated to play a role in identifying optimal biologic family therapeutic options.

\section{Conclusion}

Given the evidence to support the use of a top-down treatment approach, it is imperative to identify patients who are most likely to benefit from this strategy. Although clinical characteristics alone can help to predict a complicated disease course, these features lack the accuracy to effectively influence therapeutic decisions. Information gained from serologic testing, both qualitatively and quantitatively, can assist in determining the likelihood of a complicated CD. This personalized approach may be further improved with the incorporation of knowledge regarding NOD2/CARD15 and other novel CD-associated genetic polymorphisms. Growing evidence suggests that the aberrant IBD innate immunity reflects underlying genetic determinants in $\mathrm{CD}$ patients. The subsequent maladaptive autoimmune response is in turn reflected by the presence of IBD serologic markers. Taken together, the patient's clinical and serogenetic profile may be used to inform clinicians regarding a patient's prognostic risk and help guide treatment decisions to alter the future natural history of $\mathrm{CD}$ now.

\section{Disclosure}

Technical assistance during the development of this manuscript was provided with funding support from Prometheus Laboratories, Inc. Cyrus P Tamboli has no relevant disclosures. David B Doman discloses that he is on the speakers' bureau of Prometheus Laboratories, Abbott Pharmaceuticals, and Salix Pharmaceuticals. Amar Patel discloses that at the time of the writing of the draft, he was an employee of Peloton Advantage, which received funding support from Prometheus Laboratories.

\section{References}

1. Gasche C, Scholmerich J, Brynskov J, et al. A simple classification of Crohn's disease: report of the Working Party for the World Congresses of Gastroenterology, Vienna 1998. Inflamm Bowel Dis. 2000;6(1): $8-15$.

2. Thia K, Sandborn W, Harmsen W, Zinmeister A. The evolution of Crohn's disease (CD) behavior in a population-based cohort [abstract 1135]. Am J Gastroenterol. 2008;103 Suppl 5:S443-S444.
3. Rutgeerts P, Geboes K, Vantrappen G, Kerremans R, Coenegrachts JL, Coremans G. Natural history of recurrent Crohn's disease at the ileocolonic anastomosis after curative surgery. Gut. 1984;25(6):665-672.

4. Silverstein MD, Loftus EV, Sandborn WJ, et al. Clinical course and costs of care for Crohn's disease: Markov model analysis of a populationbased cohort. Gastroenterology. 1999;117(1):49-57.

5. Lichtenstein GR, Hanauer SB, Sandborn WJ; for the Practice Parameters Committee of the American College of Gastroenterology. Management of Crohn's disease in adults. Am J Gastroenterol. 2009;104(2): 465-483.

6. Carter MJ, Lobo AJ, Travis SP. Guidelines for the management of inflammatory bowel disease in adults. Gut. 2004;53 Suppl 5:V1-V16.

7. Hanauer SB. Positioning biologic agents in the treatment of Crohn's disease. Inflamm Bowel Dis. 2009;15(10):1570-1582.

8. Kane SV, Schoenfeld P, Sandborn WJ, Tremaine W, Hofer T, Feagan BG. Systematic review: the effectiveness of budesonide therapy for Crohn's disease. Aliment Pharmacol Ther. 2002;16(8):1509-1517.

9. Pearson DC, May GR, Fick GH, Sutherland LR. Azathioprine and 6-mercaptopurine in Crohn disease. A meta-analysis. Ann Intern Med. 1995;123(2):132-142.

10. Summers RW, Switz DM, Sessions JT Jr, et al. National Cooperative Crohn's Disease Study: results of drug treatment. Gastroenterology. 1979;77(4 Pt 2):847-869.

11. Vermeire S, Van Assche G, Rutgeerts P. Review article: altering the natural history of Crohn's disease - evidence for and against current therapies. Aliment Pharmacol Ther. 2007;25(1):3-12.

12. Faubion WA Jr, Loftus EV Jr, Harmsen WS, Zinsmeister AR, Sandborn WJ. The natural history of corticosteroid therapy for inflammatory bowel disease: a population-based study. Gastroenterology. 2001;121(2):255-260.

13. Cosnes J, Nion-Larmurier I, Beaugerie L, Afchain P, Tiret E, Gendre JP. Impact of the increasing use of immunosuppressants in Crohn's disease on the need for intestinal surgery. Gut. 2005;54(2):237-241.

14. Dhillon SL, Loftus EV, Tremaine WJ. The natural history of surgery for Crohn's disease in a population-based cohort from Olmsted County, Minnesota [abstract 825]. Am J Gastroenterol. 2005;100 Suppl:S305.

15. Cosnes J, Cattan S, Blain A, et al. Long-term evolution of disease behavior of Crohn's disease. Inflamm Bowel Dis. 2002;8(4):244-250.

16. Peyrin-Biroulet L, Loftus EV Jr, Colombel JF, Sandborn WJ. The natural history of adult Crohn's disease in population-based cohorts. Am J Gastroenterol. 2010;105(2):289-297.

17. Munkholm P, Langholz E, Davidsen M, Binder V. Disease activity courses in a regional cohort of Crohn's disease patients. Scand $J$ Gastroenterol. 1995;30(7):699-706.

18. D'Haens GR. Top-down therapy for IBD: rationale and requisite evidence. Nat Rev Gastroenterol Hepatol. 2010;7(2):86-92.

19. Schreiber S, Reinisch W, Colombel JF, et al. Early Crohn's disease shows high levels of remission to therapy with adalimumab: sub-analysis of CHARM [abstract 985]. Gastroenterology. 2007; 132 Suppl 1:A147.

20. Sandborn WJ, Colombel JF, Panes J, Scholmerich J, McConnell J, Schreiber S. Higher remission and maintenance of response rates with subcutaneous monthly certolizumab pegol in patients with recentonset Crohn's disease: data from PRECiSE 2 [abstract 1109]. Am J Gastroenterol. 2006;101:S454-S455.

21. Sandborn WJ, Rutgeerts P, Reinisch W, et al. SONIC: a randomized, double-blind, controlled trial comparing infliximab and infliximab plus azathioprine in patients with Crohn's disease naive to immunomodulators and biologic therapy [late-breaking abstract 29]. Am J Gastroenterol. 2008;103 Suppl 1:S423.

22. D'Haens G, Baert F, Van Assche G, et al. Early combined immunosuppression or conventional management in patients with newly diagnosed Crohn's disease: an open randomised trial. Lancet. 2008;371(9613): 660-667.

23. Markowitz J, Grancher K, Kohn N, Lesser M, Daum F. A multicenter trial of 6-mercaptopurine and prednisone in children with newly diagnosed Crohn's disease. Gastroenterology. 2000;119(4):895-902. 
24. Ollendorf DA, Lidsky L. Infliximab drug and infusion costs among patients with Crohn's disease in a commercially-insured setting. Am J Ther. 2006;13(6):502-506.

25. Bodger K. Economic implications of biological therapies for Crohn's disease: review of infliximab. Pharmacoeconomics. 2005;23(9): 875-888.

26. Beaugerie L, Seksik P, Nion-Larmurier I, Gendre JP, Cosnes J. Predictors of Crohn's disease. Gastroenterology. 2006;130(3):650-656.

27. Cosnes J, Carbonnel F, Beaugerie L, Le Quintrec Y, Gendre JP. Effects of cigarette smoking on the long-term course of Crohn's disease. Gastroenterology. 1996;110(2):424-431.

28. Cottone M, Rosselli M, Orlando A, et al. Smoking habits and recurrence in Crohn's disease. Gastroenterology. 1994;106(3):643-648.

29. Sands BE, Arsenault JE, Rosen MJ, et al. Risk of early surgery for Crohn's disease: implications for early treatment strategies. Am J Gastroenterol. 2003;98(12):2712-2718.

30. Silverberg MS, Satsangi J, Ahmad T, et al. Toward an integrated clinical, molecular and serological classification of inflammatory bowel disease: report of a Working Party of the 2005 Montreal World Congress of Gastroenterology. Can J Gastroenterol. 2005;19 Suppl A:5-36.

31. Vernier-Massouille G, Balde M, Salleron J, et al. Natural history of pediatric Crohn's disease: a population-based cohort study. Gastroenterology. 2008;135(4):1106-1113.

32. Bernell O, Lapidus A, Hellers G. Risk factors for surgery and postoperative recurrence in Crohn's disease. Ann Surg. 2000;231(1):38-45.

33. Solberg IC, Vatn MH, Hoie O, et al. Clinical course in Crohn's disease: results of a Norwegian population-based ten-year follow-up study. Clin Gastroenterol Hepatol. 2007;5(12):1430-1438.

34. Romberg-Camps MJ, Dagnelie PC, Kester AD, et al. Influence of phenotype at diagnosis and of other potential prognostic factors on the course of inflammatory bowel disease. Am J Gastroenterol. 2009; 104(2):371-383.

35. Dotan I. Disease behavior in adult patients: are there predictors for stricture or fistula formation? Dig Dis. 2009;27(3):206-211.

36. Langhorst J, Elsenbruch S, Koelzer J, Rueffer A, Michalsen A, Dobos GJ. Noninvasive markers in the assessment of intestinal inflammation in inflammatory bowel diseases: performance of fecal lactoferrin, calprotectin, and PMN-elastase, CRP, and clinical indices. Am J Gastroenterol. 2008;103(1):162-169.

37. Sipponen T, Savilahti E, Kärkkäinen P, et al. Fecal calprotectin, lactoferrin, and endoscopic disease activity in monitoring anti-TNF-alpha therapy for Crohn's disease. Inflamm Bowel Dis. 2008;14(10): 1392-1398.

38. Sandborn WJ, Feagan BG, Stoinov S, et al. Certolizumab pegol for the treatment of Crohn's disease. N Engl J Med. 2007;357(3):228-238.

39. Henriksen M, Jahnsen J, Lygren I, et al. C-reactive protein: a predictive factor and marker of inflammation in inflammatory bowel disease. Results from a prospective population-based study. Gut. 2008;57(11): 1518-1523

40. Schoepfer AM, Trummler M, Seeholzer P, Seibold-Schmid B, Seibold F. Discriminating IBD from IBS: comparison of the test performance of fecal markers, blood leukocytes, CRP, and IBD antibodies. Inflamm Bowel Dis. 2008;14(1):32-39.

41. Sipponen T, Savilahti E, Kolho KL, Nuutinen H, Turunen U, Farkkila M. Crohn's disease activity assessed by fecal calprotectin and lactoferrin: correlation with Crohn's disease activity index and endoscopic findings. Inflamm Bowel Dis. 2008;14(1):40-46.

42. Saxon A, Shanahan F, Landers C, Ganz T, Targan S. A distinct subset of antineutrophil cytoplasmic antibodies is associated with inflammatory bowel disease. J Allergy Clin Immunol. 1990;86(2):202-210.

43. Main J, McKenzie H, Yeaman GR, et al. Antibody to Saccharomyces cerevisiae (bakers' yeast) in Crohn's disease. BMJ. 1988;297(6656): 1105-1106.

44. Peyrin-Biroulet L, Standaert-Vitse A, Branche J, Chamaillard M. IBD serological panels: facts and perspectives. Inflamm Bowel Dis. 2007;13(12):1561-1566.
45. Papo M, Quer JC, Pastor RM, et al. Antineutrophil cytoplasmic antibodies in relatives of patients with inflammatory bowel disease. Am J Gastroenterol. 1996;91(8):1512-1515.

46. Folwaczny C, Noehl N, Endres SP, Loeschke K, Fricke H. Antineutrophil and pancreatic autoantibodies in first-degree relatives of patients with inflammatory bowel disease. Scand J Gastroenterol. 1998;33(5):523-528.

47. Vasiliauskas EA, Plevy SE, Landers CJ, et al. Perinuclear antineutrophil cytoplasmic antibodies in patients with Crohn's disease define a clinical subgroup. Gastroenterology. 1996;110(6):1810-1819.

48. Sendid B, Quinton JF, Charrier G, et al. Anti-Saccharomyces cerevisiae mannan antibodies in familial Crohn's disease. Am J Gastroenterol. 1998;93(8):1306-1310.

49. Vermeire S, Peeters M, Vlietinck R, et al. Anti-Saccharomyces cerevisiae antibodies (ASCA), phenotypes of IBD, and intestinal permeability: a study in IBD families. Inflamm Bowel Dis. 2001;7(1):8-15.

50. Sutton CL, Kim J, Yamane A, et al. Identification of a novel bacterial sequence associated with Crohn's disease. Gastroenterology. 2000;119(1):23-31.

51. Halfvarson J, Standaert-Vitse A, Jarnerot G, et al. Anti-Saccharomyces cerevisiae antibodies in twins with inflammatory bowel disease. Gut. 2005;54(9):1237-1243.

52. Seibold F, Konrad A, Flogerzi B, et al. Genetic variants of the mannanbinding lectin are associated with immune reactivity to mannans in Crohn's disease. Gastroenterology. 2004;127(4):1076-1084.

53. Muller S, Schaffer T, Flogerzi B, et al. Mannan-binding lectin deficiency results in unusual antibody production and excessive experimental colitis in response to mannose-expressing mild gut pathogens. Gut. 2010;59(11):1493-1500.

54. Mei L, Targan SR, Landers CJ, et al. Familial expression of antiEscherichia coli outer membrane porin $\mathrm{C}$ in relatives of patients with Crohn's disease. Gastroenterology. 2006;130(4):1078-1085.

55. Torok HP, Glas J, Hollay HC, et al. Serum antibodies in first-degree relatives of patients with IBD: a marker of disease susceptibility? A follow-up pilot-study after 7 years. Digestion. 2005;72(2-3):119-123.

56. Israeli E, Grotto I, Gilburd B, et al. Anti-Saccharomyces cerevisiae and antineutrophil cytoplasmic antibodies as predictors of inflammatory bowel disease. Gut. 2005;54(9):1232-1236.

57. Standaert-Vitse A, Jouault T, Vandewalle P, et al. Candida albicans is an immunogen for anti-Saccharomyces cerevisiae antibody markers of Crohn's disease. Gastroenterology. 2006;130(6):1764-1775.

58. Berlin T, Zandman-Goddard G, Blank M, et al. Autoantibodies in nonautoimmune individuals during infections. Ann NYAcad Sci. 2007; 1108:584-593.

59. Condino AA, Hoffenberg EJ, Accurso F, et al. Frequency of ASCA seropositivity in children with cystic fibrosis. J Pediatr Gastroenterol Nurs. 2005;41(1):23-26.

60. Lachenal F, Nkana K, Nove-Josserand R, Fabien N, Durieu I. Prevalence and clinical significance of auto-antibodies in adults with cystic fibrosis. Eur Respir J. 2009;34(5):1079-1085.

61. Makharia GK, Sachdev V, Gupta R, Lal S, Pandey RM. AntiSaccharomyces cerevisiae antibody does not differentiate between Crohn's disease and intestinal tuberculosis. Dig Dis Sci. 2007;52(1):33-39.

62. Granito A, Zauli D, Muratori P, et al. Anti-Saccharomyces cerevisiae and perinuclear anti-neutrophil cytoplasmic antibodies in coeliac disease before and after gluten-free diet. Aliment Pharmacol Ther. 2005;21(7): 881-887.

63. Sakly W, Mankai A, Sakly N, et al. Anti-Saccharomyces cerevisiae antibodies are frequent in type 1 diabetes. Endocr Pathol. 2010;21(2): $108-114$.

64. Muratori P, Muratori L, Guidi M, et al. Anti-Saccharomyces cerevisiae antibodies (ASCA) and autoimmune liver diseases. Clin Exp Immunol. 2003;132(3):473-476.

65. Riente L, Chimenti D, Pratesi F, et al. Antibodies to tissue transglutaminase and Saccharomyces cerevisiae in ankylosing spondylitis and psoriatic arthritis. J Rheumatol. 2004;31(5):920-924. 
66. Sendid B, Colombel JF, Jacquinot PM, et al. Specific antibody response to oligomannosidic epitopes in Crohn's disease. Clin Diagn Lab Immunol. 1996;3(2):219-226.

67. Standaert-Vitse A, Sendid B, Joossens M, et al. Candida albicans colonization and ASCA in familial Crohn's disease. Am J Gastroenterol. 2009;104(7):1745-1753.

68. Anand BS. Diagnosis of gastrointestinal tuberculosis. Trop Gastroenterol. 1994;15(4):179-185.

69. Hoffman IE, Demetter P, Peeters M, et al. Anti-Saccharomyces cerevisiae IgA antibodies are raised in ankylosing spondylitis and undifferentiated spondyloarthropathy. Ann Rheum Dis. 2003;62(5): 455-459.

70. Zauli D, Ghetti S, Grassi A, et al. Anti-neutrophil cytoplasmic antibodies in type 1 and 2 autoimmune hepatitis. Hepatology. 1997;25(5): 1105-1107.

71. Mow WS, Vasiliauskas EA, Lin YC, et al. Association of antibody responses to microbial antigens and complications of small bowel Crohn's disease. Gastroenterology. 2004;126(2):414-424.

72. Arnott ID, Landers CJ, Nimmo EJ, et al. Sero-reactivity to microbial components in Crohn's disease is associated with disease severity and progression, but not NOD2/CARD15 genotype. Am J Gastroenterol. 2004;99(12):2376-2384

73. Papadakis KA, Yang H, Ippoliti A, et al. Anti-flagellin (CBir1) phenotypic and genetic Crohn's disease associations. Inflamm Bowel Dis 2007;13(5):524-530.

74. Dubinsky MC, Lin YC, Dutridge D, et al. Serum immune responses predict rapid disease progression among children with Crohn's disease: immune responses predict disease progression. Am J Gastroenterol. 2006;101(2):360-367.

75. Dubinsky MC, Kugathasan S, Mei L, et al. Increased immune reactivity predicts aggressive complicating Crohn's disease in children. Clin Gastroenterol Hepatol. 2008;6(10):1105-1111.

76. Ippoliti A, Devlin S, Mei L, et al. Combination of innate and adaptive immune alterations increased the likelihood of fibrostenosis in Crohn's disease. Inflamm Bowel Dis. 2010;16(8):1279-1285.

77. Sandborn WJ, Loftus EV Jr, Colombel JF, et al. Evaluation of serologic disease markers in a population-based cohort of patients with ulcerative colitis and Crohn's disease. Inflamm Bowel Dis. 2001;7(3):192-201.

78. Peeters M, Joossens S, Vermeire S, Vlietinck R, Bossuyt X, Rutgeerts P. Diagnostic value of anti-Saccharomyces cerevisiae and antineutrophil cytoplasmic autoantibodies in inflammatory bowel disease. Am J Gastroenterol. 2001;96(3):730-734

79. Klebl FH, Bataille F, Hofstadter F, Herfarth H, Scholmerich J, Rogler G. Optimising the diagnostic value of anti-Saccharomyces cerevisiae-antibodies (ASCA) in Crohn's disease. Int J Colorectal Dis. 2004;19(4):319-324.

80. Reese GE, Constantinides VA, Simillis C, et al. Diagnostic precision of anti-Saccharomyces cerevisiae antibodies and perinuclear antineutrophil cytoplasmic antibodies in inflammatory bowel disease. Am J Gastroenterol. 2006;101(10):2410-2422.

81. Solberg IC, Lygren I, Cvancarova M, et al. Predictive value of serologic markers in a population-based Norwegian cohort with inflammatory bowel disease. Inflamm Bowel Dis. 2009;15(3):406-414.

82. Ferrante M, Henckaerts L, Joossens M, et al. New serological markers in inflammatory bowel disease are associated with complicated disease behaviour. Gut. 2007;56(10):1394-1403.

83. Ashorn S, Honkanen T, Kolho KL, et al. Fecal calprotectin levels and serological responses to microbial antigens among children and adolescents with inflammatory bowel disease. Inflamm Bowel Dis. 2009;15(2):199-205.

84. Benor S, Russell GH, Silver M, Israel EJ, Yuan Q, Winter HS. Shortcomings of the Inflammatory Bowel Disease Serology 7 panel. Pediatrics. 2010;125(6):1230-1236.

85. Morganstern JA, Shakir T, Chawla A. Is CBir1 a predictor of pediatric inflammatory bowel disease? [abstract 2]. J Pediatr Gastroenterol Nutr. 2007;45:E1.
86. Rashid F, Bechtold ML, Puli SR, Bragg JD. Utility of IBD serology tests: experience of an academic medical center. The Internet $J$ Gastroenterol. 2011:10(1).

87. Landers CJ, Cohavy O, Misra R, et al. Selected loss of tolerance evidenced by Crohn's disease-associated immune responses to auto- and microbial antigens. Gastroenterology. 2002;123(3):689-699.

88. Lodes MJ, Cong Y, Elson CO, et al. Bacterial flagellin is a dominant antigen in Crohn disease. J Clin Invest. 2004;113(9):1296-1306.

89. Targan SR, Landers CJ, Yang H, et al. Antibodies to CBir1 flagellin define a unique response that is associated independently with complicated Crohn's disease. Gastroenterology. 2005;128(7):2020-2028.

90. Dotan I, Fishman S, Dgani Y, et al. Antibodies against laminaribioside and chitobioside are novel serologic markers in Crohn's disease. Gastroenterology. 2006;131(2):366-378.

91. Joossens S, Reinisch W, Vermeire S, et al. The value of serologic markers in indeterminate colitis: a prospective follow-up study. Gastroenterology. 2002;122(5):1242-1247.

92. Forcione DG, Rosen MJ, Kisiel JB, Sands BE. Anti-Saccharomyces cerevisiae antibody (ASCA) positivity is associated with increased risk for early surgery in Crohn's disease. Gut. 2004;53(8):1117-1122.

93. Klebl FH, Bataille F, Bertea CR, et al. Association of perinuclear antineutrophil cytoplasmic antibodies and anti-Saccharomyces cerevisiae antibodies with Vienna classification subtypes of Crohn's disease. Inflamm Bowel Dis. 2003;9(5):302-307.

94. Vasiliauskas EA, Kam LY, Karp LC, Gaiennie J, Yang H, Targan SR. Marker antibody expression stratifies Crohn's disease into immunologically homogeneous subgroups with distinct clinical characteristics. Gut. 2000;47(4):487-496.

95. Fleshner PR, Vasiliauskas EA, Kam LY, et al. High level perinuclear antineutrophil cytoplasmic antibody (pANCA) in ulcerative colitis patients before colectomy predicts the development of chronic pouchitis after ileal pouch-anal anastomosis. Gut. 2001;49(5):671-677.

96. Fleshner P, Ippoliti A, Dubinsky M, et al. Both preoperative perinuclear antineutrophil cytoplasmic antibody and anti-CBir1 expression in ulcerative colitis patients influence pouchitis development after ileal pouch-anal anastomosis. Clin Gastroenterol Hepatol. 2008;6(5):561-568.

97. Abreu MT, Taylor KD, Lin YC, et al. Mutations in NOD2 are associated with fibrostenosing disease in patients with Crohn's disease. Gastroenterology. 2002;123(3):679-688.

98. Brant SR, Picco MF, Achkar JP, et al. Defining complex contributions of NOD2/CARD15 gene mutations, age at onset, and tobacco use on Crohn's disease phenotypes. Inflamm Bowel Dis. 2003;9(5):281-289.

99. Schoepfer AM, Schaffer T, Mueller S, et al. Phenotypic associations of Crohn's disease with antibodies to flagellins A4-Fla2 and Fla-X, ASCA, p-ANCA, PAB, and NOD2 mutations in a Swiss Cohort. Inflamm Bowel Dis. 2009;15(9):1358-1367.

100. Lesage S, Zouali H, Cezard JP, et al. CARD15/NOD2 mutational analysis and genotype-phenotype correlation in 612 patients with inflammatory bowel disease. Am J Hum Genet. 2002;70(4):845-857.

101. Ippoliti AF, Devlin S, Yang H, et al. The relationship between abnormal innate and adaptive immune function and fibrostenosis in Crohn's disease patients [abstract 127]. Gastroenterology. 2006;130:A24-A25.

102. Hugot JP, Chamaillard M, Zouali H, et al. Association of NOD2 leucine-rich repeat variants with susceptibility to Crohn's disease. Nature. 2001;411(6837):599-603.

103. Ogura Y, Bonen DK, Inohara N, et al. A frameshift mutation in NOD2 associated with susceptibility to Crohn's disease. Nature. 2001; 411(6837):603-606.

104. Franke A, McGovern DP, Barrett JC, et al. Genome-wide metaanalysis increases to 71 the number of confirmed Crohn's disease susceptibility loci. Nat Genet. 2010;42(12):1118-1125.

105. Economou M, Trikalinos TA, Loizou KT, Tsianos EV, Ioannidis JP. Differential effects of NOD2 variants on Crohn's disease risk and phenotype in diverse populations: a metaanalysis. Am J Gastroenterol. 2004;99(12):2393-2404 
106. Yazdanyar S, Kamstrup PR, Tybjaerg-Hansen A, Nordestgaard BG. Penetrance of NOD2/CARD15 genetic variants in the general population. CMAJ. 2010;182(7):661-665.

107. Helio T, Halme L, Lappalainen M, et al. CARD15/NOD2 gene variants are associated with familially occurring and complicated forms of Crohn's disease. Gut. 2003;52(4):558-562.

108. Ahmad T, Armuzzi A, Bunce M, et al. The molecular classification of the clinical manifestations of Crohn's disease. Gastroenterology. 2002;122(4):854-866.

109. Weersma RK, Stokkers PC, van Bodegraven AA, et al. Molecular prediction of disease risk and severity in a large Dutch Crohn's disease cohort. Gut. 2009;58(3):388-395.

110. Dassopoulos T, Frangakis C, Cruz-Correa M, et al. Antibodies to Saccharomyces cerevisiae in Crohn's disease: higher titers are associated with a greater frequency of mutant NOD2/CARD15 alleles and with a higher probability of complicated disease. Inflamm Bowel Dis. 2007;13(2):143-151.

111. Devlin SM, Yang H, Ippoliti A, et al. NOD2 variants and antibody response to microbial antigens in Crohn's disease patients and their unaffected relatives. Gastroenterology. 2007;132(2):576-586.

112. Joossens M, Van Steen K, Branche J, et al. Familial aggregation and antimicrobial response dose-dependently affect the risk for Crohn's disease. Inflamm Bowel Dis. 2010;16(1):58-67.

113. Takedatsu H, Taylor KD, Mei L, et al. Linkage of Crohn's diseaserelated serological phenotypes: NFKB1 haplotypes are associated with anti-CBir1 and ASCA, and show reduced NF-kappaB activation. Gut. 2009;58(1):60-67.

114. Walker LJ, Aldhous MC, Drummond HE, et al. Anti-Saccharomyces cerevisiae antibodies (ASCA) in Crohn's disease are associated with disease severity but not NOD2/CARD15 mutations. Clin Exp Immunol. 2004;135(3):490-496.

115. Lichtenstein GR, Barken DM, Eggleston L, et al. A novel algorithm-based approach using clinical parameters, genetic and serological markers to effectively predict aggressive disease behavior in patients with Crohn's disease [abstract 207]. Presented at Digestive Disease Week; New Orleans, LA; May 1-6, 2010.
116. Arnott ID, McNeill G, Satsangi J. An analysis of factors influencing short-term and sustained response to infliximab treatment for Crohn's disease. Aliment Pharmacol Ther. 2003;17(12):1451-1457.

117. Maser EA, Villela R, Silverberg MS, Greenberg GR. Association of trough serum infliximab to clinical outcome after scheduled maintenance treatment for Crohn's disease. Clin Gastroenterol Hepatol. 2006;4(10):1248-1254.

118. Sandborn WJ, Landers CJ, Tremaine WJ, Targan SR. Association of antineutrophil cytoplasmic antibodies with resistance to treatment of left-sided ulcerative colitis: results of a pilot study. Mayo Clin Proc. 1996;71(5):431-436.

119. Mow WS, Landers CJ, Steinhart AH, et al. High-level serum antibodies to bacterial antigens are associated with antibiotic-induced clinical remission in Crohn's disease: a pilot study. Dig Dis Sci. 2004;49(7-8): 1280-1286.

120. Esters N, Vermeire S, Joossens S, et al. Serological markers for prediction of response to anti-tumor necrosis factor treatment in Crohn's disease. Am J Gastroenterol. 2002;97(6):1458-1462.

121. Ferrante M, Vermeire S, Katsanos KH, et al. Predictors of early response to infliximab in patients with ulcerative colitis. Inflamm Bowel Dis. 2007;13(2):123-128.

122. Hlavaty T, Ferrante M, Henckaerts L, Pierik M, Rutgeerts P, Vermeire S. Predictive model for the outcome of infliximab therapy in Crohn's disease based on apoptotic pharmacogenetic index and clinical predictors. Inflamm Bowel Dis. 2007;13(4):372-379.

123. Dubinsky MC, Mei L, Friedman M, et al. Genome wide association (GWA) predictors of anti-TNFalpha therapeutic responsiveness in pediatric inflammatory bowel disease. Inflamm Bowel Dis. 2009;16(8): 1357-1366.

124. Devlin SM, Dubinsky MC. Determination of serologic and genetic markers aid in the determination of the clinical course and severity of patients with IBD. Inflamm Bowel Dis. 2008;14(1):125-128.
Clinical and Experimental Gastroenterology

\section{Publish your work in this journal}

Clinical and Experimental Gastroenterology is an international, peerreviewed, open access journal, publishing all aspects of gastroenterology in the clinic and laboratory, including: Pathology, pathophysiology of gastrointestinal disease; Investigation and treatment of gastointestinal disease; Pharmacology of drugs used in the alimentary tract;

\section{Dovepress}

Immunology/genetics/genomics related to gastrointestinal disease. This journal is indexed on CAS. The manuscript management system is completely online and includes a very quick and fair peer-review system. Visit http://www.dovepress.com/testimonials.php to read real quotes from published authors. 